\title{
Microstructure evolution and strengthening mechanisms in friction-stir welded Al-Mg-Sc alloy
}

\author{
I. Vysotskiy, D. Zhemchuzhnikova, S. Malopheyev, S. Mironov *, R. Kaibyshev \\ Laboratory of Mechanical Properties of Nanoscale Materials and Superalloys, Belgorod National Research University, Pobeda 85, Belgorod, 308015, Russia
}

\section{A R T I C L E I N F O}

\section{Keywords:}

Aluminium alloys

Second-phase particles

Friction-stir welding

Electron backscatter diffraction

Microstructure

Microstructure-strength relationship

\begin{abstract}
A B S T R A C T
The present work was undertaken to evaluate the effect of second-phase particles on microstructure evolution during friction-stir welding (FSW). To this end, Al-6.0Mg-0.35Mn-0.2Sc-0.1Zr alloy containing insoluble nanoscale $\mathrm{Al}_{3}(\mathrm{Sc}, \mathrm{Zr})$ dispersoids was used as a program material. A particular emphasis was given to an establishment of a microstructure-strength relationship in the welded material.

It was found that pinning effect of the $\mathrm{Al}_{3}(\mathrm{Sc}, \mathrm{Zr})$ precipitates efficiently suppressed grain-boundary migration and promoted a concentration of slip activity in heavily-stressed near-grain-boundary regions. This gave rise to a preferential development of deformation-induced boundaries in the latter areas. Due to a complex character of slip at the grain boundaries, the newly evolved grains had nearly random crystallographic orientations. As a result, the final microstructure evolved in stir zone was characterized by relatively-fine grain size, poorlydeveloped texture and large fraction of high-angle boundaries.

The retention of the coherent dispersoids as well as considerable grain refinement occurring during FSW resulted in substantial material hardening in the stir zone.
\end{abstract}

\section{Introduction}

Friction-stir welding (FSW) is an innovative solid-state joining technique $[1,2]$. Due to excellent service properties of produced welds, this technology is sometimes referred as one of the most significant achievements in the field of joining of structural materials. From a standpoint of mechanics, FSW represents a unique thermo-mechanical process involving very large strain at high temperature and strain rate. It is worth noting that material behavior under such extreme deformation conditions is not studied well and thus FSW attracts not only commercial but also an academic interest.

The extensive recent research has shown that the microstructural evolution during FSW is a complex process. In relatively simple singlephase materials, it typically involves a combination of continuous(cDRX) and discontinuous (dDRX) dynamic recrystallizations [3-7]. Moreover, mechanical twinning [e.g. 5, 7], annealing twinning [e.g. 3-5] and even grain convergence [7] may also occur in particular cases. It is sometimes believed that activation of particular microstructural mechanism is dictated by crystal structure and stacking fault energy but may also be influenced by a welding temperature [8].

On the other hand, a structural response of alloys containing second- phase particles is much less clear. During conventional thermomechanical processing, the particles are well known to exert a considerable effect on recrystallization behavior and mechanical properties. Accordingly, it is of interest to examine their influence on the formation of microstructure under extreme FSW conditions and mechanical behavior of weld joints. However, the secondary particles often dissolve at typical FSW temperatures (e.g. [9-11]) and therefore their impact on recrystallization behavior remains poorly understood.

The present work attempts to shed some light on this issue. To this end, an $\mathrm{Al}-\mathrm{Mg}$-Sc alloy containing coherent $\mathrm{Al}_{3}(\mathrm{Sc}, \mathrm{Zr})$ dispersoids, which are stable until the melting point [12-31] and thus should affect microstructure evolution during FSW, was examined. Indeed, the FSW-induced microstructures in such materials are typically found to be unusual. Specifically, they are often characterized by fine- or ultrafine-grains [12-30], very weak crystallographic texture [19,20,26] and relatively large fraction of high-angle boundaries [12,14-16,20,24, $26,27]$. These structural characteristics are typically attributed to the particle influence but the exact mechanism is not clear, to the best of the authors' knowledge.

To provide a deeper insight into this issue, the present work was focused on investigation of microstructure evolution in a typical $\mathrm{Al}-\mathrm{Mg}$ -

\footnotetext{
* Corresponding author.

E-mail address: mironov@bsu.edu.ru (S. Mironov).
} 
Sc alloy during FSW. To this end, electron backscatter diffraction (EBSD) and transmission electron microscopy (TEM) were employed for thorough microstructural characterization. In addition, the obtained results were used to elucidate the contributions of various hardening mechanisms to the overall strength of the welded material and thus to establish the microstructure-strength relationship.

\section{Experimental}

The material used in the present investigation was a commercial Al$6.0 \mathrm{Mg}-0.35 \mathrm{Mn}-0.2 \mathrm{Sc}-0.1 \mathrm{Zr}$ (all in wt.\%) alloy fabricated by semicontinuous casting $[28,30,31]$. To precipitate the $\mathrm{Al}_{3} \mathrm{Sc}$ dispercoids, the produced ingot was annealed at $360^{\circ} \mathrm{C}$ for $12 \mathrm{~h}$. This route produced equiaxed grain structure with a mean grain diameter of $35 \mu \mathrm{m}$, which contained second-phase particles evenly distributed in grain interior. The latter ones included relatively coarse $(\sim 40 \mathrm{~nm}) \mathrm{Al}_{6} \mathrm{Mn}$ dispersoids as well as nano-scale $(\sim 6 \mathrm{~nm}) \mathrm{Al}_{3}(\mathrm{Sc}, \mathrm{Zr})$ precipitates. The volume fraction of the particles was measured to be $0.65 \mathrm{vol} \%$ and $0.12 \mathrm{vol} \%$, respectively. Further microstructural details have been described elsewhere [31].

For the FSW experiment, the annealed ingot was sliced into 10-mmthickness sheets. The welding process was performed by using AccuStir $1004 \mathrm{FSW}$ machine operating at a spindle rate of $500 \mathrm{rpm}$, a feed rate of $150 \mathrm{~mm} / \mathrm{min}$ and a tool tilt angle of $2.5^{\circ}$. As it was found in the previous work [22], this combination of welding variables ensures defect-free joining and promotes a good combination of mechanical properties. The welding tool was fabricated from a tool steel and consisted of a shoulder of $16 \mathrm{~mm}$ in diameter and a threaded probe tapered from $6 \mathrm{~mm}$ at the tool shoulder to $4.8 \mathrm{~mm}$ at the tip; the probe length was $6.5 \mathrm{~mm}$. To provide a full-thickness joining, double-side FSW was conducted in the same welding direction. To maintain consistency with FSW literature, the principal directions of welding geometry were denoted throughout as welding direction (WD), transverse direction (TD) and normal direction (ND).

Microstructural observations were conducted with optical microscopy, EBSD and TEM. In all cases, the microstructural examinations were made on transverse cross-section of the welds, i.e., TD $\times$ ND plane. For optical microscopy, the samples were prepared by using conventional metallographic techniques followed by final etching in Keller's reagent $\left(2 \mathrm{ml} \mathrm{HF}+3 \mathrm{ml} \mathrm{HCl}+5 \mathrm{ml} \mathrm{HNO}_{3}+190 \mathrm{ml} \mathrm{H}_{2} \mathrm{O}\right)$. A suitable surface finish for EBSD was obtained by vibratory polishing with colloidal silica for $24 \mathrm{~h}$. TEM specimens were obtained by electropolishing in a solution of $25 \%$ nitric acid in ethanol at an applied potential of $19.5 \mathrm{~V}$.

TEM study was performed using a JEM-2100EX transmission electron microscope operating at $200 \mathrm{kV}$. EBSD analysis was conducted with a Hitachi S-4300SE field-emission-gun scanning electron microscope equipped with TSL OIM ${ }^{\mathrm{TM}}$ software and operated at accelerated voltage of $25 \mathrm{kV}$ and a scan step size of $0.2 \mu \mathrm{m}$. The relevant statistics of EBSD measurements is summarized in Table 1. To minimize misindexing error, five Kikuchi bands were used for indexing of each acquired diffraction pattern. To improve reliability of EBSD data, the small grains comprising three or fewer pixels were automatically removed from the

Table 1

Statistics of EBSD measurements.

\begin{tabular}{llll}
\hline $\begin{array}{l}\text { Location of EBSD } \\
\text { map }\end{array}$ & $\begin{array}{l}\text { Area of each EBSD } \\
\text { map, } \mu \mathrm{m}^{2}\end{array}$ & $\begin{array}{l}\text { Number of pixels in } \\
\text { each map }\end{array}$ & $\begin{array}{l}\text { Number of } \\
\text { grains }\end{array}$ \\
\hline $\begin{array}{l}0.75 \mathrm{~mm} \text { from } \\
\text { stir zone }\end{array}$ & $250 \times 200$ & $1,444,328$ & 664 \\
$\begin{array}{l}0.5 \mathrm{~mm} \text { from stir } \\
\text { zone }\end{array}$ & & 697 \\
$\begin{array}{l}0.25 \mathrm{~mm} \text { from } \\
\text { stir zone }\end{array}$ & 2210 \\
$\begin{array}{l}\text { Stir zone } \\
\text { extremity }\end{array}$ & 11,842 \\
\hline
\end{tabular}

maps using the standard grain-dilation option of the TSL software. To eliminate spurious boundaries caused by orientation noise, a lower-limit boundary misorientation cut-off of $2^{\circ}$ was used. A $15^{\circ}$ criterion was used to differentiate low-angle boundaries (LABs) and high-angle boundaries (HABs). Grain size was quantified by applying the grain-reconstruction approach [32], i.e., considering each grain as a circle with equivalent area and calculating the associated circle-equivalent diameter. To get additional insight into microstructure distribution in the welded material, microhardness map was acquired across the weld cross section. Vickers microhardness data were obtained by applying a load of $100 \mathrm{~g}$ with a dwell time of $15 \mathrm{~s}$.

To establish the microstructure-strength relationship in the welded material, the longitudinal tensile tests were used. To this end, tensile specimens were machined from the stir-zone material. The specimens were cut parallel to the WD, and had a gauge section of $16 \mathrm{~mm}$ in length, $3 \mathrm{~mm}$ in width, and $2 \mathrm{~mm}$ in thickness. Appropriate tensile specimens were also made from the base material. In all cases, tension tests to failure were conducted at ambient temperature and a nominal strain rate of $2 \times 10^{-3} \mathrm{~s}^{-1}$ using an Instron 5882 testing machine.

\section{Results}

\subsection{Low-magnification overview of welds}

Low-magnification optical image of a typical weld is shown in Fig. 1a. A distinct stir zone is seen. In this zone, a clear evidence for two overlapping FSW passes (conducted during double-side welding) is visible. In both cases, the stir zone somewhat enlarged towards upper (or bottom) surfaces thus presumably reflecting a pronounced influence of the tool shoulder on material flow. Remarkably, no characteristic onionring structure was found in the stir zone. On the other hand, a relatively dark optical contrast was noted in several locations including advancing side, near-surface layer as well as an overlapping area of the upper and lower FSW passes.

In order to provide an additional insight into FSW-induced microstructures, microhardness map was measured across the weld zone, as shown in Fig. 1b. For clarity, the contours of the tool probes were also indicated in the map (dotted lines). The microhardness measurements had confirmed inhomogeneous character of microstructure distribution within the stir zone. As follows from comparison of Fig. 1a and b, the microstructural regions with relatively dark optical contrast exhibited comparatively high hardness.

\subsection{Broad aspects of grain structure evolution}

To investigate grain structure development during FSW, the microstructure in a transition region between the base material and the stir zone was examined. In this area, the parent microstructure gradually transforms into the final stir-zone one thus enabling to ascertain the broad aspects of microstructural changes. To avoid a specific character of material flow presumably occurring in the optically-dark regions discussed in the previous section, microstructural observations were focused at the mid-thickness of the retreating side of the upper stir zone, as indicated by a white rectangle in Fig. 1a. A composite EBSD map taken from this area is presented in Fig. 2a; the selected areas of the map are given at higher magnifications in Fig. $2 \mathrm{~b}-\mathrm{d}$. The grain-size statistics derived from the EBSD maps is shown in Fig. 3.

Near outer edge of the transition region, the extensive formation of LABs was found (Fig. 2a and b). Importantly, this process was most pronounced near original grain boundaries and was accompanied by significant crystallographic rotations in these $\operatorname{areas}^{1}$ (Fig. 2b). This

\footnotetext{
${ }^{1}$ In EBSD orientation maps in Fig. 2a, crystallographic rotations in the neargrain-boundary regions appeared as essential changes of orientation contrast (i. e., color) in these areas.
} 

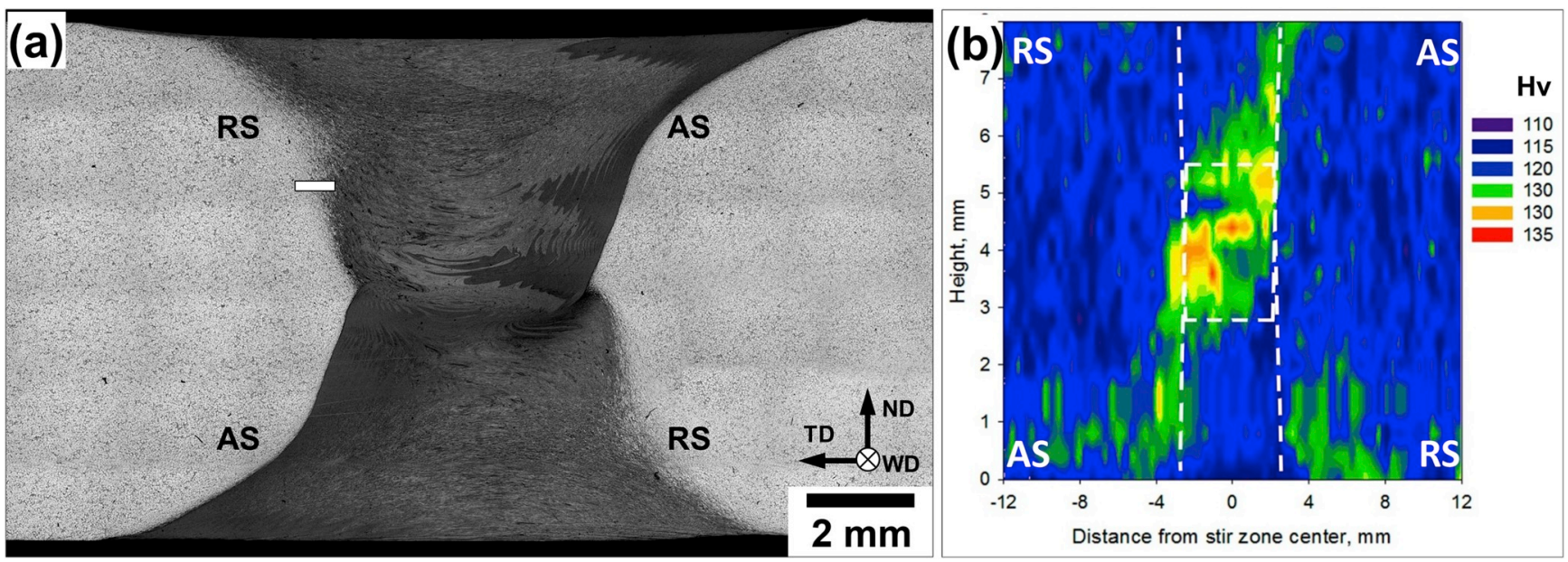

Fig. 1. Low-magnification overview of transversal cross sections of friction-stir weld (a) and microhardness map measured across the weld (b). In (a), white rectangle indicates EBSD map shown in Fig. 2a. In (b), dotted lines outline contours of the tool probes; the microhardness color code is given in the top right corner. RS and AS abbreviate retreating side and advancing side, respectively. (For interpretation of the references to color in this figure legend, the reader is referred to the Web version of this article.)
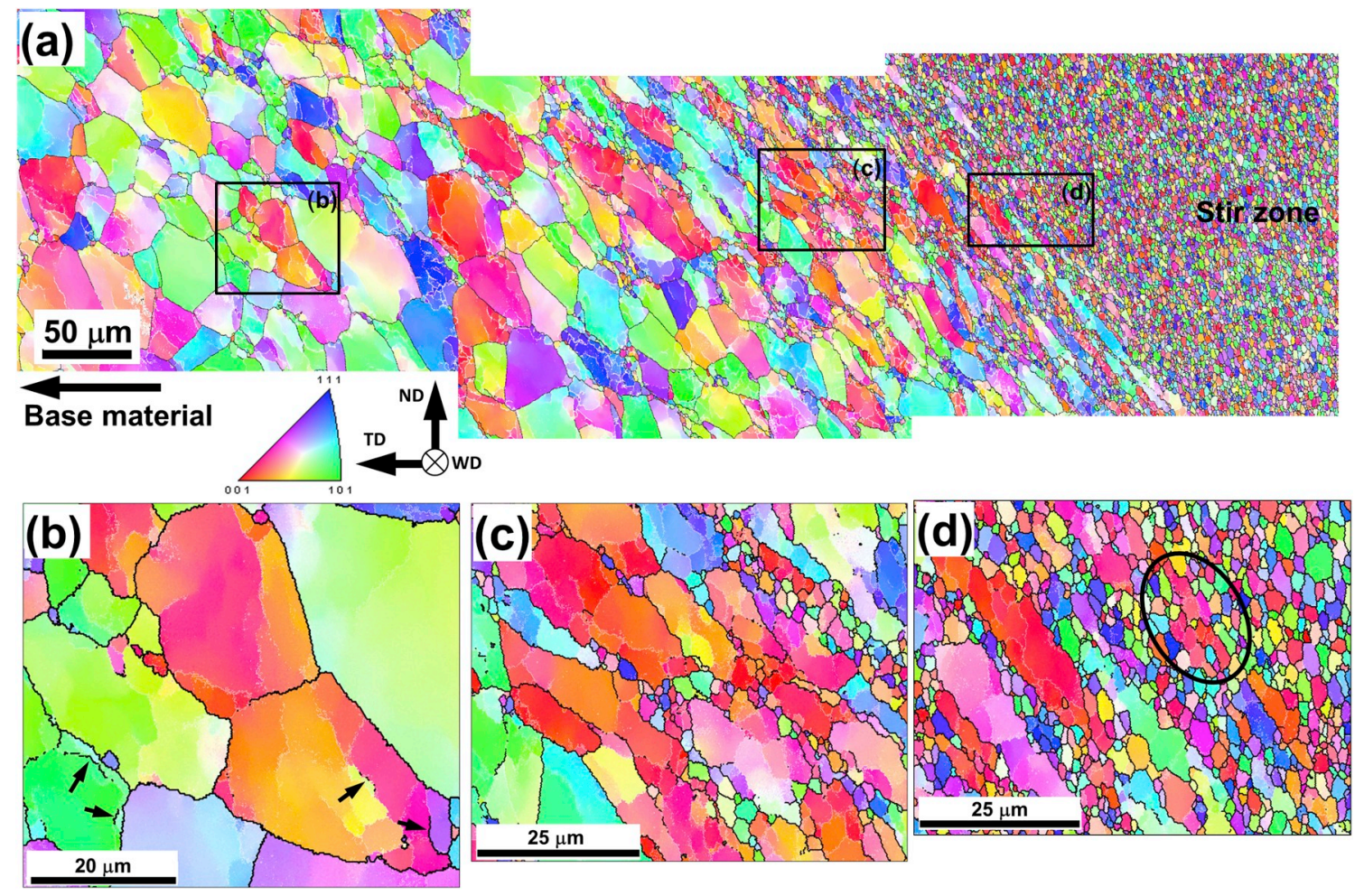

Fig. 2. Composite EBSD orientation map taken from thermo-mechanically affected zone (a) with selected areas given at higher magnifications in (b)-(d). In the map, individual grains are colored according to crystal orientation relative to the WD and color code triangle is shown in the bottom left corner of (a); LABs and HABs are depicted as white and black lines, respectively. See Section 3.2 for details. (For interpretation of the references to color in this figure legend, the reader is referred to the Web version of this article.)

observation perhaps indicated a considerable difference in slip activity between the grain interior and the near-grain-boundary areas. As a result of the enhanced slip in the latter areas, the deformation-induced boundaries rapidly accumulated misorientation. Moreover, some of their segments have already transformed into HABs (arrows in Fig. 2b).

Approaching the stir zone, original grains were significantly sheared to form a distinct flow pattern around the stir zone (Fig. 2a and c), thus presumably reflecting a geometrical effect of the imposed strain. On the other hand, new fine grains nucleated at prior grain-boundaries, thus giving rise to a necklace-type structure (Fig. 2c). Accordingly, grain-size distribution became bimodal (Fig. 3). In all observed cases, the new grains appeared to originate from a gradual transformation of LABs to HABs. No clear evidences of grain-boundary bulging was found. It is also important to note that the newly nucleated grains typically had crystallographic orientations essentially different from those of the original grains (Fig. 2c).

At the stir zone extremity, volume fraction of fine equiaxed grains increased significantly (Figs. 2d and 3). On the other hand, original grains were significantly sheared and their thickness approached to the subgrain size (Fig. 2d). From a thorough analysis of EBSD data, it seemed 


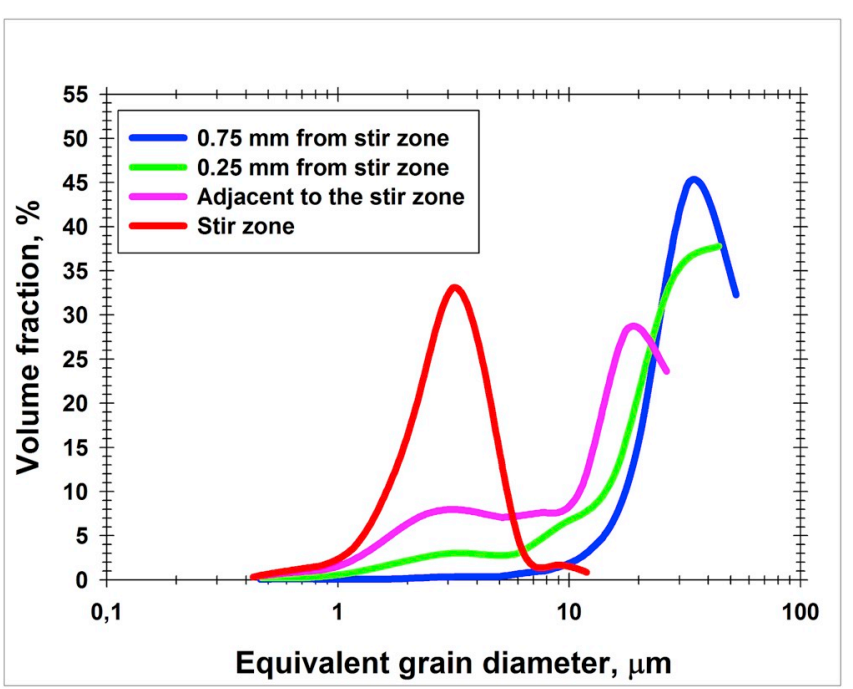

Fig. 3. Evolution of grain-size distribution as function of distance to the stir zone. See Section 3.2 for details.

that the fine grains originated from progressive substructure development within the parent grains (selected area in Fig. 2d). This process eventually broke down the heavily-sheared original grains into reasonably uniform fine-grained structure with relatively high $\mathrm{HAB}$ fraction in the stir zone (Figs. 2a and 3). The evolved microstructure was broadly similar to that typically observed in friction-stirred Al-Mg-Sc alloys [12-30].

Remarkably, a typical grain diameter of the fine grains did not alter significantly approaching the stir zone, being $\sim 3 \mu \mathrm{m}$ in size in all cases (Fig. 3a). This presumably evidenced no gross grain-boundary migration occurring during FSW.

\subsection{Texture formation}

To provide an additional insight into grain-structure evolution, the texture formation was also studied. To this end, orientation data were derived from appropriate EBSD maps, arranged as 111 and 110 pole figures and summarized in Fig. 4a-c. ${ }^{2}$ It should be noted that the textural data were appropriately rotated to align their reference frames with presumed geometry of simple shear strain during FSW, as has been recently discussed by Fonda et al. [33]. For comparative purpose, ideal simple shear textures expected for face-centered cubic metals were also shown in Fig. 4d.

In all cases, the measured textures were relatively weak and poorly developed. This areeed well with previous texture observations in friction-stirred Al-Mg-Sc [19,20,26]. Nevertheless, a more or less clear evidence of $\{h k l\}\langle 110>$ fiber texture was found in the present study (compare Fig. 4a-c with Fig. 4d).

In order to establish a better understanding of the grain refinement process, the bimodal grain structure evolved in close proximity to the stir zone (Fig. 2d) was partitioned into domains comprising fine-grains (grain size $<10 \mu \mathrm{m}$ ) and coarse-grains (grain size $\geq 10 \mu \mathrm{m}$ ) by using standard option of the used EBSD software. To avoid confusion in definition of grains in heavily deformed microstructure, the term "grain" in the present work was applied to denote a crystallite bordered by a continuous HAB perimeter in EBSD map. The orientation data extracted from such domains were shown in Fig. 5. Surprisingly, the pole figures in both cases were found to be qualitative similar. It is worth noting,

\footnotetext{
${ }^{2}$ In this work, no clear FSW-induced texture was found at the distances exceeding $\sim 0.25 \mathrm{~mm}$ away from the stir zone. For simplicity, these textural data were not shown in Fig. 4.
}

meanwhile, that the texture of the fine-grained domain exhibited relatively-large orientation spread and relatively-lower intensity (compare Fig. 5a and b).

To quantify orientation difference between the fine- and coarsegrained domains, appropriate orientation distribution functions (ODFs) were calculated. For comparative purpose, ODF for the stir zone material was also obtained. The selected sections of the ODFs $\left(\phi_{2}=0^{\circ}\right.$ and $\phi_{2}=45^{\circ}$ ) were shown in Fig. 6 . The volume fractions of various textural components were summarized in Table 2.

From the ODFs, it was found that the coarse-grained domain was characterized by a typical $\{h k l\}\langle 110>$ fiber texture with pronounced $B /$ $\bar{B}\{112\}<110>$ components (Fig. 6a, Table 2). Such texture is often reported to develop in friction-stirred aluminum alloys [33]. Therefore, material flow within the coarse parent grains was probably more or less close to that normally observed during FSW. On the hand, a development of new fine grains led to a gradual randomization of the typical FSW texture (Fig. 6b and c, Table 2). Considering a preferential nucleation of the fine-grains at prior grain-boundaries, the above effect presumably indicated a complex (or even chaotic) character of slip in these areas.

\subsection{Dislocation structure and second-phase particles}

To examine the second-phase particles as well as dislocation structure, TEM observations were done in the thermo-mechanically affected zone and the stir zone with typical results being summarized in Figs. 7 and 8.

In thermo-mechanically affected zone, an increased dislocation density was found in vicinity of original grain boundaries (Fig. 7a). This observation presumably indicated an enhanced slip activity in these areas thus being in the line with EBSD data discussed in Section 3.2. Surprisingly, subtle serrations of the grain-boundaries were found (Fig. 7b). It is important to emphasize, however, that the typical size of the bulges was as small as $\sim 0.1 \mu \mathrm{m}$, thus being very low. Another remarkable observation was a development of relatively coarse semicoherent particles in grain interior (arrows in Fig. 7c).

In the stir zone, TEM observations confirmed the formation of the relatively fine-grained microstructure (Fig. 8a). The dislocation density was measured to be $1.3 \times 10^{13} \mathrm{~m}^{-2}$, thus being relatively low. Nevertheless, sub-boundary structure could be sometimes revealed within the relatively coarse-grained remnants (Fig. $8 \mathrm{~b}$ ). This was in the line with EBSD measurements showing extensive LAB-to-HAB transformation in transition zone, as discussed in Section 3.2. As expected, the secondphase particles had survived in the stir zone (Fig. 8a and c); moreover, the careful microstructural measurements revealed no notable changes in the particle volume fraction. On the other hand, a subtle particle coarsening was found. Specifically, the mean diameter of $\mathrm{Al}_{3}(\mathrm{Sc}, \mathrm{Zr})$ and $\mathrm{Al}_{6} \mathrm{Mn}$ dispersoids was measured to become $11 \mathrm{~nm}$ and $44 \mathrm{~nm}$, respectively.

\subsection{Tensile behavior}

Typical diagrams recorded during longitudinal tensile tests of the base- and stir zone materials are shown in Fi.9. It is seen that FSW promoted a substantial hardening effect. The possible mechanism of this phenomenon is discussed in Section 4.2.

An important characteristic of the mechanical behavior of both studied materials was repetitive oscillations observed along the deformation diagrams. Such serrations are typical for Al-Mg alloys (including the material studied in the present work), being typically referred to as the Portevin-Le Chatelier (PCL) effect. The PCL effect is sometimes attributed to an enhanced mobility of solutes which results in the solute atmospheres at dislocations and thus promotes an instability of material flow. A clear enhancement of this phenomenon in the stir zone (Fig. 9) is thought to be associated with relatively fine grain size in this material 

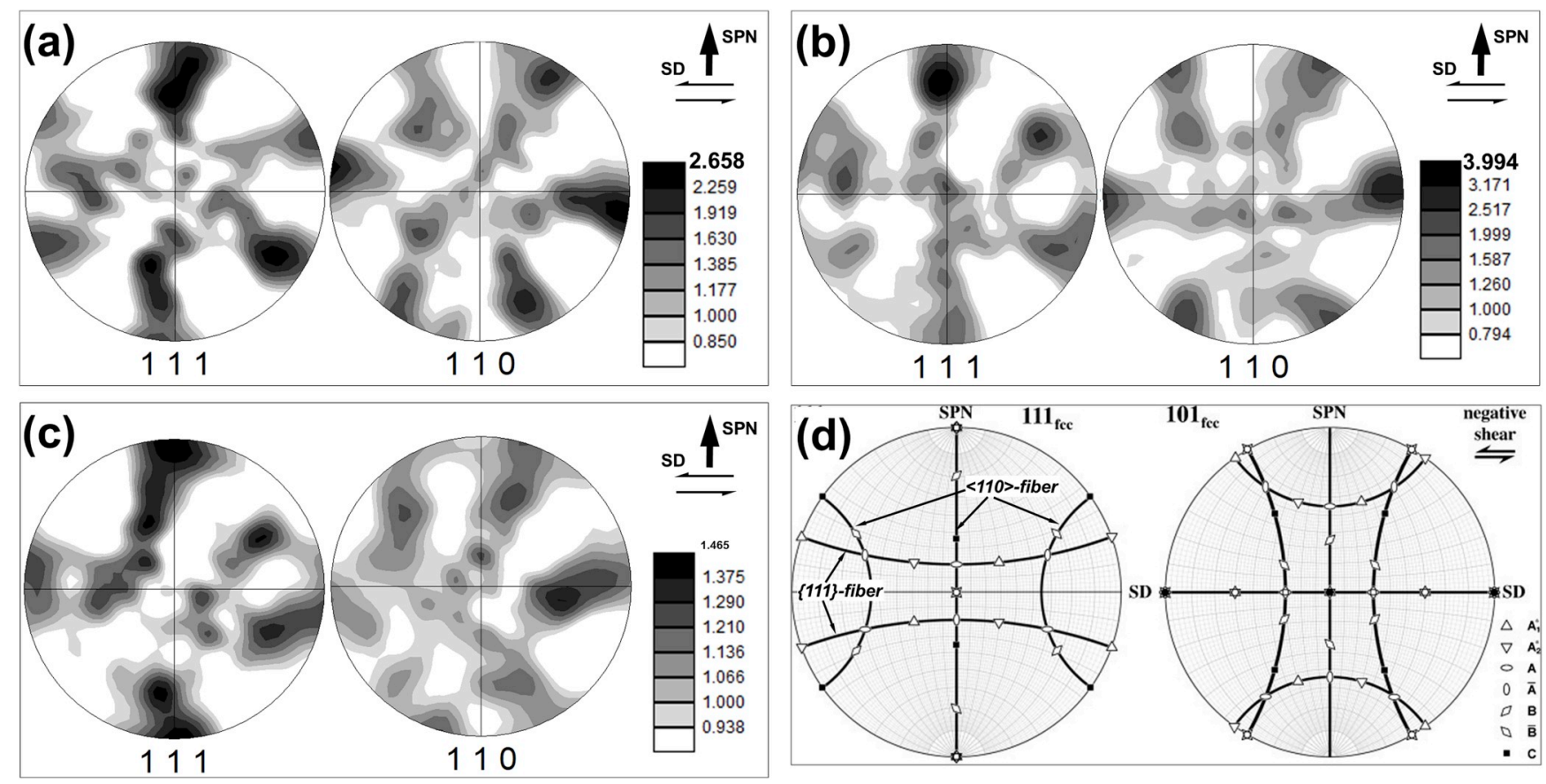

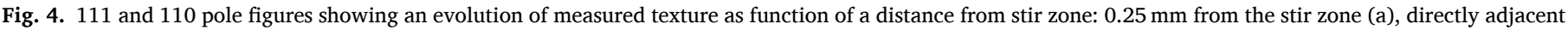

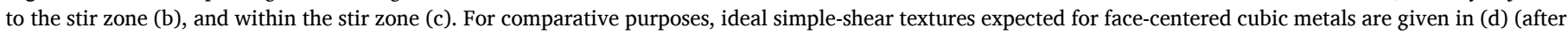

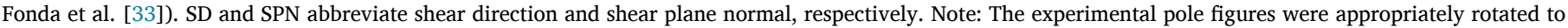
align their reference frames with assumed geometry of simple shear strain. See Section 3.3 for details.
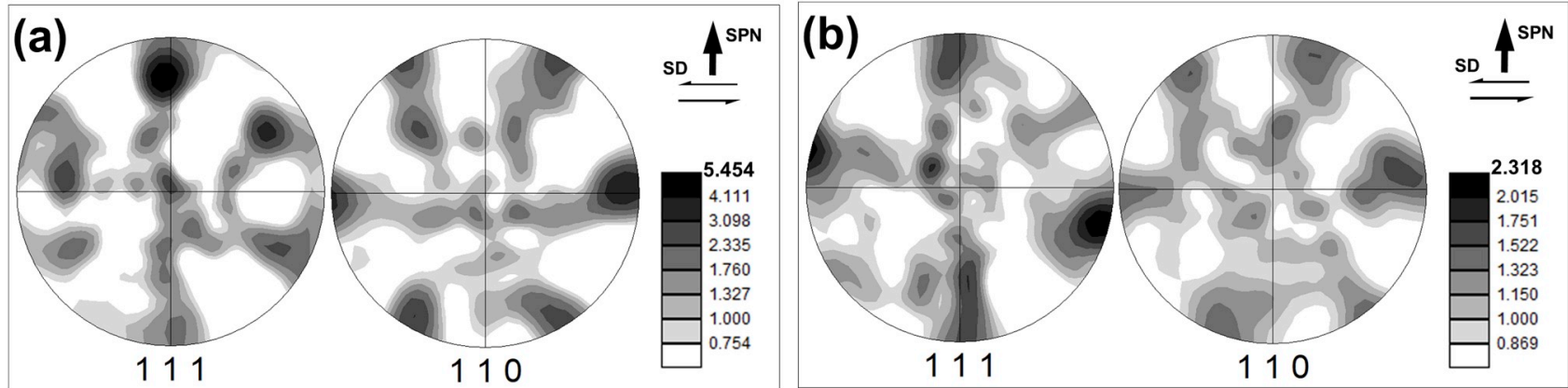

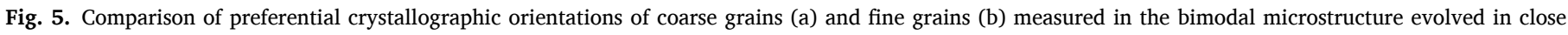

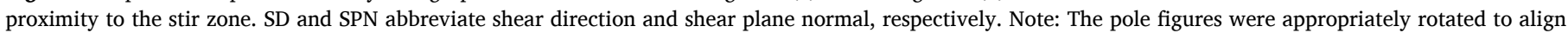
their reference frames with assumed geometry of simple shear strain. See Section 3.3 for details.

condition (Fig. 2) and the concomitant increase in dislocation density.

Another remarkable issue was a more or less clear Luders strain at the early stage of plastic deformation of the stir zone material (Fig. 9). This phenomenon is well accepted to originate from an abrupt increase of density of mobile dislocations at the onset of the plastic strain, which usually leads to strain localization within the Luders bands. In the present study, the observed effect was likely attributable to the relatively low dislocation density in the stir zone material (Fig. 8a).

\section{Discussion}

\subsection{Effect of second-phase particles on microstructure evolution}

Since the second-phase particles survived at FSW temperature, they are expected to influence microstructural behavior during welding. The possible mechanism of this effect is considered in the present section.

Thorough microstructural examinations revealed no recrystallization nuclei in vicinity of the secondary particles. This perhaps evidenced that the so-called particle-stimulated nucleation (PSN) mechanism [34] unlikely contributed to the microstructural evolution in the present study. This, however, was not surprising considering a very fine size of precipitates in the studied material (much less than $1 \mu \mathrm{m}$ ), which is widely accepted to be insufficient for activation of the PSN mechanism [34].

Moreover, no clear evidences of discontinuous recrystallization at all were found, despite the subtle serrations were observed along the boundaries of the parent grains (Fig. 7b). This effect is also thought to be associated with the second-phase particles. Specifically, the size of the stable recrystallization nucleus is well accepted to be determined by a balance between its surface energy and the energy of the eliminated dislocations. This relation is typically expressed as $D>3 \gamma / 0.5 \rho G b^{2}$, where $D$ is the critical nucleus size, $\gamma$ is surface energy of high-angle boundaries $\left(\sim 0.3 \mathrm{~J} / \mathrm{m}^{2}\right), \rho$ denotes dislocation density (taken to be $10^{15} \mathrm{~m}^{-2}$ ), $G$ is shear modulus ( $=26 \mathrm{GPa}$ ), and $b$ is the Burgers vector $(=0.286 \mathrm{~nm})$ [34]. This criterion leads to a critical nucleus size of $\sim 1 \mu \mathrm{m}$, which is significantly greater that a typical dimension of grain-boundary bulges revealed in the present work (Fig. 7b). It is believed therefore that the survived precipitates essentially inhibited 

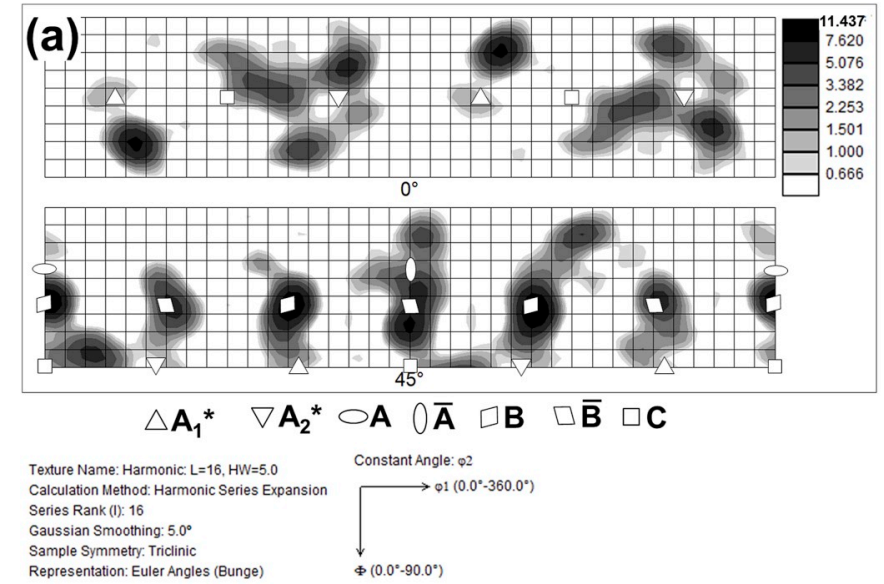
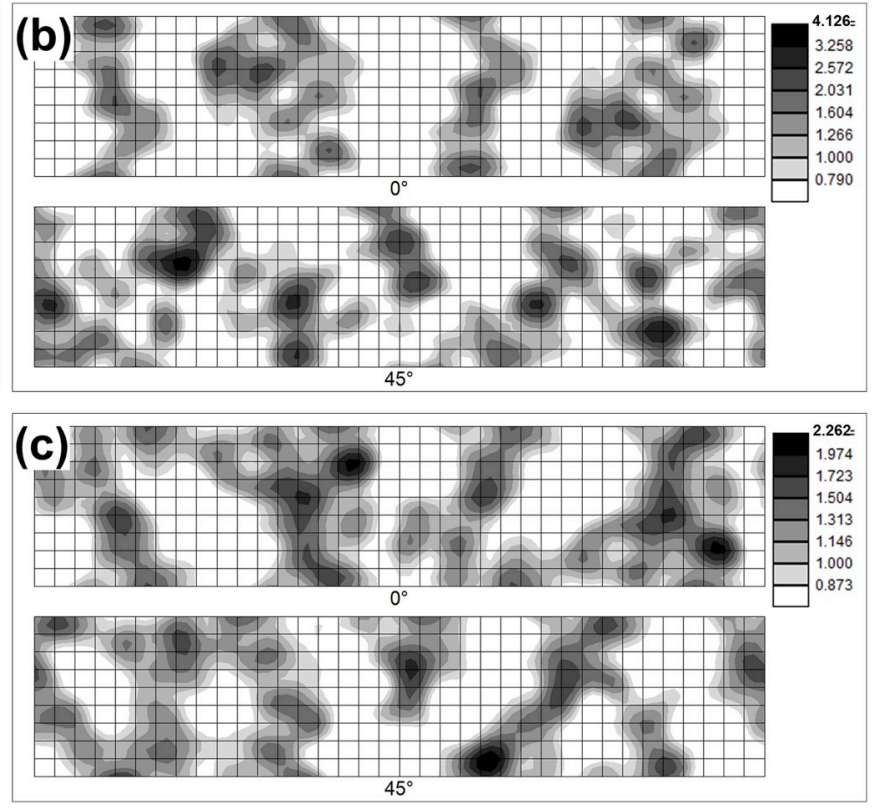

Fig. 6. Selected portions $\left(\varphi_{2}=0^{\circ}\right.$ and $\left.\varphi_{2}=45^{\circ}\right)$ of orientation distribution functions (ODFs) showing preferential crystallographic orientations of the coarse- and fine grains in the bimodal microstructure evolved in close proximity to the stir zone (a \& b, respectively) and the stir zone texture (c). For simplicity, positions of ideal simple-shear texture components are shown in (a). See Section 3.3 for details.

Table 2

Volume fractions of textural components in selected microstructural regions.

\begin{tabular}{|l|c|c|c|}
\hline \multirow{2}{*}{$\begin{array}{c}\text { Crystallographic } \\
\text { orientations }\end{array}$} & \multicolumn{2}{|c|}{$\begin{array}{c}\text { Microstructural region directly adjacent to } \\
\text { stir zone }\end{array}$} & \multirow{2}{*}{ Stir zone } \\
\cline { 2 - 3 } & Coarse grains & Fine grains & \\
\hline \multicolumn{3}{|c|}{ Fiber textures } \\
$\{111\}<u v w>$ & 13.2 & 7.0 & 5.8 \\
$\{h k l\}<110>$ & 22.4 & 11.7 & 9.1 \\
\hline \multicolumn{3}{|c|}{ Textural components } \\
$A_{1}^{*}(111)[\overline{1} 1 \overline{2}]$ & 1.4 & 1.4 & 1.1 \\
$A_{2}^{*}(111)[11 \overline{2}]$ & 0.9 & 0.8 & 0.9 \\
$A(1 \overline{1})[110]$ & 0.9 & 1.1 & 1.0 \\
$\bar{A}(1 \overline{1} 1)[\overline{1} 1 \overline{1} 0]$ & 1.9 & 1.1 & 0.9 \\
$B(1 \overline{1} 2)[\overline{1} 10]$ & 6.5 & 1.6 & 0.8 \\
$\bar{B}(\overline{1} 1 \overline{2})[\overline{1} \overline{1} 0]$ & 3.8 & 1.0 & 0.8 \\
$C\{001\}<110>$ & 1.3 & 1.0 & 0.4 \\
\hline
\end{tabular}

Note: The predominant textural components are highlighted with gray

grain boundary migration and thus suppressed a development of the discontinuous recrystallization.

On the other hand, EBSD measurements conclusively demonstrated that the grain structure evolution was governed by a gradual LAB-to$\mathrm{HAB}$ transformation, i.e., a mechanism which virtually fits a definition of continuous recrystallization. This conclusion agrees well with recent observations of microstructure evolution during hot severe plastic deformation of Al-Mg-Sc alloys [26,35-37]. Importantly, however, that the above process occurred preferentially near original grain boundaries (Fig. 2b-d) and the evolved fine grains had nearly random crystallographic orientations (Table 2). The specific character of the microstructural changes is also thought to be associated with the secondary particles.

Specifically, the particle pinning effect should inhibit a rearrangement of dislocations into deformation-induced boundaries, thus virtually suppressing the continuous recrystallization. This process could efficiently develop only in relatively heavily-stressed regions, i.e. near original grain boundaries. Due to the complex stress fields in these areas induced by the grain-to-grain interactions, the resulting slip activity gives rise to the very weak deformation texture in the stir zone (Fig. 6c and Table 2). In turn, a nearly stochastic nature of crystallographic orientations of neighboring grains resulted in relatively-high HAB fraction in the stir zone, in close agreement with literature data [12, 14-16,20,24,26,27].

\subsection{Microstructure-strength relationship}

To investigate an effect of FSW on microstructure-strength relationship, various contributions to overall strength of the base- and stir zone materials were evaluated on the basis of the detailed microstructural examination given above. The relevant microstructural
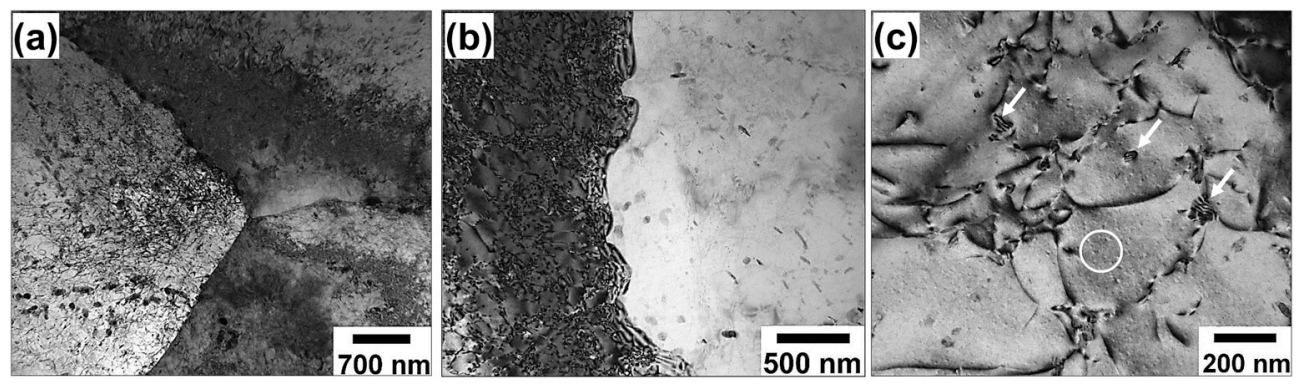

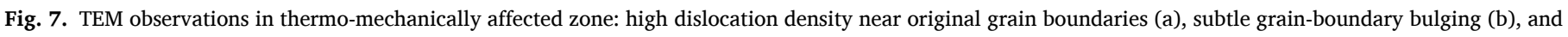
second-phase particles (c). In (c), arrows exemplify semi-coherent particles whereas selected area shows $\mathrm{Al}_{3}(\mathrm{Sc}, \mathrm{Zr}$ ) dispersoids. See Section 3.4 for details. 

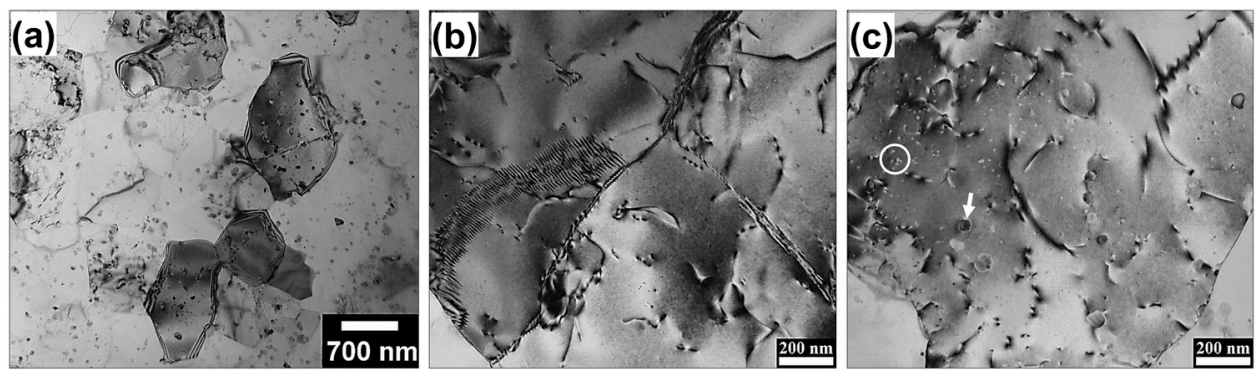

Fig. 8. TEM observations in stir zone: fine-grained structure (a), dislocation sub-boundaries (b), and second-phase particles (c). In (c), arrow exemplifies an $\mathrm{Al}_{6} \mathrm{Mn}$ particle whereas selected area shows $\mathrm{Al}_{3}(\mathrm{Sc}, \mathrm{Zr})$ dispersoids. See Section 3.4 for details.

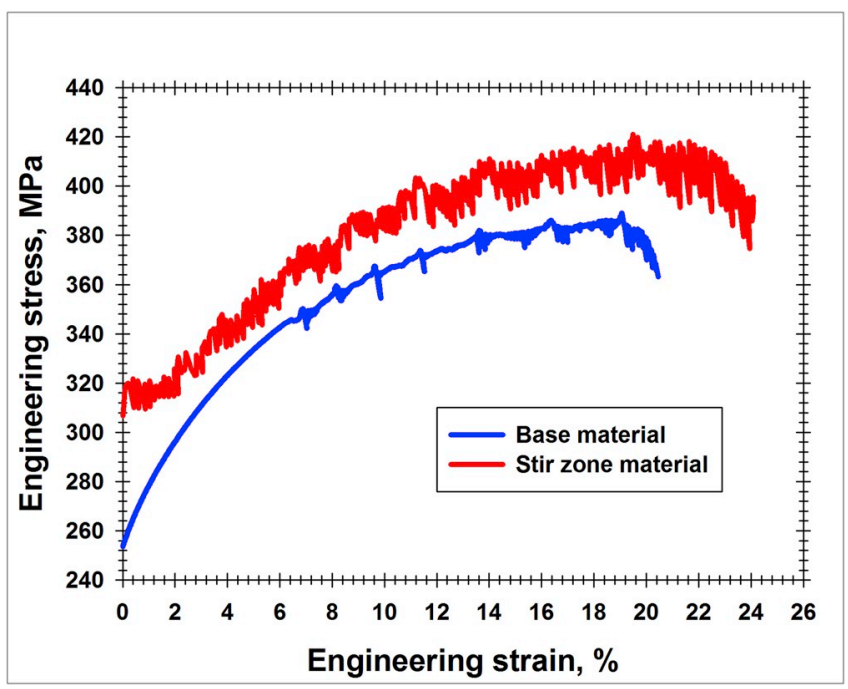

Fig. 9. Typical deformation diagrams of the stir zone material and the base material.

characteristics were summarized in Table 3.

Considering low dislocation density in both studied material conditions and assuming that different strengthening mechanisms act independently (and thus have additive contributions), the total strength $\sigma$ may be expressed as $\sigma=\sigma_{0}+\sigma_{G B}+\sigma_{p}$, where $\sigma_{0}$ is the strength of the $\mathrm{Al}-\mathrm{Mg}$ solid solution, $\sigma_{G B}$ is the grain boundary strengthening, and $\sigma_{p}$ denotes the precipitation hardening.

In the studied material, the threshold stress can be evaluated as $\sigma_{0}=$ $\sigma_{o}^{A l}+\sigma_{s s}$, in which $\sigma_{o}^{A l}$ is the threshold stress in pure aluminum $(\approx 10 \mathrm{MPa})$ and $\sigma_{s s}$ is a solid-solution strengthening. In turn, the latter one can be quantified as $\sigma_{s s}=H_{M g} C_{M g}^{n}+\sigma_{\text {trace }}+\sigma_{D S A}$, where $H_{M g}$ is solidsolution strengthening efficiency of magnesium solutes (taken to be 13.8 $\mathrm{MPa} / \mathrm{wt} . \% \mathrm{Mg}$ [38-40]), $C_{M g}$ is wt.\% of magnesium (6\% in the program material), $n$ is a material constant, which is typically taken to be 1 in Al-Mg alloys [38,41]), $\sigma_{\text {trace }}$ defines the strengthening effect of trace solutes ( $\approx 24 \mathrm{MPa}$ in Al-Mg alloys [38-40]), and $\sigma_{D S A}$ is a hardening effect associated with the dynamic strain aging. The latter one is usually

Table 3

Microstructural characteristics of base material and stir zone material.

\begin{tabular}{|c|c|c|c|c|c|}
\hline \multirow[t]{2}{*}{$\begin{array}{l}\text { Material } \\
\text { condition }\end{array}$} & \multirow[t]{2}{*}{$\begin{array}{l}\text { Mean grain size, } \\
\mu \mathrm{m}\end{array}$} & \multicolumn{2}{|c|}{$\begin{array}{l}\text { Particle volume } \\
\text { fraction, vol } \%\end{array}$} & \multicolumn{2}{|c|}{$\begin{array}{l}\text { Mean particle } \\
\text { diameter, nm }\end{array}$} \\
\hline & & $\begin{array}{l}\mathrm{Al}_{3}(\mathrm{Sc}, \\
\mathrm{Zr})\end{array}$ & $\mathrm{Al}_{6} \mathrm{Mn}$ & $\begin{array}{l}\mathrm{Al}_{3}(\mathrm{Sc}, \\
\mathrm{Zr})\end{array}$ & $\mathrm{Al}_{6} \mathrm{Mn}$ \\
\hline Base material & 30 & 0.12 & 0.65 & 6 & 40 \\
\hline $\begin{array}{l}\text { Stir zone } \\
\text { material }\end{array}$ & 3 & 0.12 & 0.70 & 11 & 44 \\
\hline
\end{tabular}

estimated as a maximal magnitude of the stress drop observed in deformation diagrams $[42,43]$; in the present study, it was measured to be $11 \mathrm{MPa}$ for the base material and $17 \mathrm{MPa}$ for the stir zone material. The calculated magnitudes of strength of $\mathrm{Al}-\mathrm{Mg}$ solution were summarized in Table 4.

The grain-boundary strengthening is conventionally described in terms of the well-known Hall-Petch relationship viz. $\sigma_{G B}=k_{H P} d^{-0.5}$, in which $k_{H P}$ is the Hall-Petch constant (taken to be $0.17 \mathrm{MPa} \mathrm{m}^{0.5}$ in the present work [22,38-40,42,44]), and $d$ denotes the mean grain size. Assuming the mean grain size for the base material to be $30 \mu \mathrm{m}$ and that for the stir zone material of $3 \mu \mathrm{m}$ (Fig. 3), the grain boundary strengthening for these material states was calculated to be $29 \mathrm{MPa}$ and $98 \mathrm{MPa}$, respectively (Table 4).

Considering two types of precipitates contributing to the strength of the examined materials (i.e., $\mathrm{Al}_{3}(\mathrm{Sc}, \mathrm{Zr})$ and $\left.\mathrm{Al}_{6} \mathrm{Mn}\right)$, the integral hardening effect could be represented as $\sigma_{p}=\sigma_{A l_{3}(S c, Z r)}+\sigma_{A l_{6} M n}$. Accounting for a very dispersive nature of the $\mathrm{Al}_{3}(\mathrm{Sc}, \mathrm{Zr})$ dispersoids and coherent relationship with aluminum matrix, the associated strengthening effect was assumed to be governed by a particle cutting mechanism. According to Kending et al. [44], the latter one could be quantified as $\sigma_{A l_{3}(S c, Z r)}=$ $M \frac{\gamma^{1.5}}{b^{2}}\left(\frac{r f}{G}\right)^{0.5}$, where $M$ is Taylor factor (taken to be 3.06), $\gamma$ denotes an energy of anti-phase boundary $\left(=0.185 \mathrm{~J} / \mathrm{m}^{2}[44]\right), r$ is the particle radius, and $f$ is the particle volume fraction. Taking the particle radius to be $3.2 \mathrm{~nm}$ for the base material and $5.5 \mathrm{~nm}$ for the stir zone material (Table 3), the concomitant hardening effects were predicted to be 36.5 MPa and 48 MPa, respectively (Table 4).

On the other hand, $\mathrm{Al}_{6} \mathrm{Mn}$ precipitates were relatively coarse in size $(\sim 50 \mathrm{~nm})$ and thus the particle bowing (i.e., Orowan-) mechanism was suggested to operate in this case. Accordingly, the increment in material strength could be calculated as $\sigma_{A l_{6} M n}=0.84 \frac{M G b}{\lambda}$, where $\lambda$ is the particle mean spacing; in turn, the latter one can be evaluated as $\lambda=\sqrt{\frac{2 \pi r^{2}}{3 f}}$. Taking the particle volume fraction and mean radius as shown in Table 3, the hardening effect was predicted to be around $52 \mathrm{MPa}$ for the base material and $58 \mathrm{MPa}$ for the stir zone material ${ }^{3}$ (Table 4).

In total, the above calculations predicted an increase of the material strength from $246 \mathrm{MPa}$ in the base material to $338 \mathrm{MPa}$ in the stir zone, which was very close to the measured variation in the yield strength (Table 4). It is clear from Table 4 that the strengthening effect was primarily associated with grain refinement as well as with retention of $\mathrm{Al}_{3}(\mathrm{Sc}, \mathrm{Zr})$ dispersoids in the stir zone.

\footnotetext{
${ }^{3}$ It should be noted that some tendency for clustering of $\mathrm{Al}_{6} \mathrm{Mn}$ precipitations was found, i.e., the spatial distribution of these dispersoids was not entirely uniform. Accordingly, the real strengthening effect imparted by these particles is believed to be lower than the predicted one. This issue, however, warrants further study.
} 
Table 4

Contribution of different strengthening mechanisms to yield strength.

\begin{tabular}{|c|c|c|c|c|c|c|}
\hline \multirow[t]{2}{*}{$\begin{array}{l}\text { Material } \\
\text { condition }\end{array}$} & \multirow[t]{2}{*}{$\begin{array}{l}\text { Strength of } \mathrm{Al}-\mathrm{Mg} \text { solution, } \\
\mathrm{MPa}\end{array}$} & \multirow[t]{2}{*}{$\begin{array}{l}\text { Grain-boundary strengthening, } \\
\mathrm{MPa}\end{array}$} & \multicolumn{2}{|c|}{$\begin{array}{l}\text { Precipitation } \\
\text { hardening, MPa }\end{array}$} & \multirow[t]{2}{*}{$\begin{array}{l}\text { Total calculated strength, } \\
\mathrm{MPa}\end{array}$} & \multirow[t]{2}{*}{$\begin{array}{l}\text { Measured yield strength, } \\
\mathrm{MPa}\end{array}$} \\
\hline & & & $\begin{array}{l}\mathrm{Al}_{3}(\mathrm{Sc}, \\
\mathrm{Zr})\end{array}$ & $\mathrm{Al}_{6} \mathrm{Mn}$ & & \\
\hline Base material & 128 & 29 & 37 & 52 & 246 & 225 \\
\hline Stir zone material & 134 & 98 & 48 & 58 & 338 & 315 \\
\hline
\end{tabular}

\section{Conclusions}

The present work attempted to ascertain an influence of the secondphase particles on microstructure evolution during FSW. To this end, Al$6.0 \mathrm{Mg}-0.35 \mathrm{Mn}-0.2 \mathrm{Sc}-0.1 \mathrm{Zr}$ alloy, which contained insoluble nano-scale $\mathrm{Al}_{3}(\mathrm{Sc}, \mathrm{Zr})$ precipitates, was selected as a program material. The extensive microstructural observations were used to elucidate the contributions of various hardening mechanisms to the overall strength of the welded material and thus to establish a microstructure-strength relationship. The main conclusions derived from this work were as follows.

As expected, $\mathrm{Al}_{3}(\mathrm{Sc}, \mathrm{Zr})$ dispersoids survived during FSW. Due to the particle pinning effect, an enhanced slip activity was observed in heavily-stressed near-grain-boundary regions. This gave rise to a preferential development of deformation-induced boundaries in these areas. As a result of the complex stress fields generated by grain-to-grain interactions, the newly evolved grains had nearly random crystallographic orientations and, accordingly, the developed microstructure was characterized by a relatively high HAB fraction. Moreover, the particles also essentially retarded grain-boundary mobility thus suppressing a growth of the nucleated grains and resulting in a relatively fine-grained microstructure.

The preservation of $\mathrm{Al}_{3}(\mathrm{Sc}, \mathrm{Zr})$ precipitates and drastic grain refinement occurring during FSW promoted substantial material strengthening in the stir zone.

\section{Data availability}

The raw/processed data required to reproduce these findings cannot be shared at this time due to technical or time limitations.

\section{Declaration of competing interest}

The authors declare that they have no known competing financial interest or personal relationships that could have appeared to influence the work reported in this paper.

\section{Acknowledgments}

This work was supported by the Ministry of Science and Higher Education of the Russian Federation under the agreement №14.584.21.0023 (ID number RFMEFI58417X0023). A staff of Joint Research Center at Belgorod National Research University is acknowledged for technical assistance.

\section{References}

[1] R.S. Mishra, Z.Y. Ma, Friction stir welding and processing, Mater. Sci. Eng. R 50 (2005) 1-78, https://doi.org/10.1016/j.mser.2005.07.001.

[2] P.L. Threadgill, A.J. Leonard, H.R. Shercliff, P.J. Withers, Friction stir welding of aluminum alloys, Int. Mater. Rev. 54 (2009) 49-93, https://doi.org/10.1179/ $174328009 X 411136$.

[3] S. Mironov, Y.S. Sato, H. Kokawa, H. Inoue, S. Tsuge, Structural response of superaustenitic stainless steel to friction stir welding, Acta Mater. 59 (2011) 5472-5481, https://doi.org/10.1016/j.actamat.2011.05.021.

[4] J. Jeon, S. Mironov, Y.S. Sato, H. Kokawa, S.H.C. Park, S. Hirano, Friction stir spot welding of single-crystal austenitic stainless steel, Acta Mater. 59 (2011) 7439-7449, https://doi.org/10.1016/j.actamat.2011.09.013.
[5] S. Mironov, K. Inagaki, Y.S. Sato, H. Kokawa, Development of grain structure during friction-stir welding of $\mathrm{Cu}-30 \mathrm{Zn}$ brass, Philos. Mag. 94 (2014) 3137-3147, https://doi.org/10.1080/14786435.2014.951712.

[6] S. Mironov, K. Inagaki, Y.S. Sato, H. Kokawa, Effect of welding temperature on microstructure of friction-stir welded aluminum alloy 1050, Metall. Mater. Trans. A 46 (2015) 783-790, https://doi.org/10.1007/s11661-014-2651-0.

[7] S. Mironov, T. Onuma, Y.S. Sato, H. Kokawa, Microstructure evolution during friction-stir welding of AZ31 magnesium alloy, Acta Mater. 100 (2015) 301-312, https://doi.org/10.1016/j.actamat.2015.08.066.

[8] S. Mironov, K. Inagaki, Y.S. Sato, H. Kokawa, Microstructural evolution of pure copper during friction-stir welding, Philos. Mag. 95 (2015) 367-381, https://doi. org/10.1080/14786435.2015.1006293.

[9] G. Liu, L.M. Murr, C.S. Niou, J.C. McClure, F.R. Vega, Microstructural aspects of the friction-stir welding of 6061-T6 aluminum, Scr. Mater. 37 (1997) 355-361, https://doi.org/10.1016/S1359-6462(97)00093-6.

[10] Y.S. Sato, H. Kokawa, M. Enomoto, S. Jogan, Microstructural evolution of 6063 aluminum during friction-stir welding, Metall. Mater. Trans. A 30 (1999) 2429-2437, https://doi.org/10.1007/s11661-999-0251-1.

[11] Y.S. Sato, H. Kokawa, M. Enomoto, S. Jogan, T. Hashimoto, Precipitation sequence in friction stir weld of 6063 aluminum during aging, Metall. Mater. Trans. A 30 (1999) 3125-3130, https://doi.org/10.1007/s11661-999-0223-5.

[12] F.C. Liu, Z.Y. Ma, L.Q. Chen, Low-temperature superplasticity of Al-Mg-Sc alloy produced by friction stir processing, Scr. Mater. 60 (2009) 968-971, https://doi. org/10.1016/j.scriptamat.2009.02.021.

[13] F.C. Liu, Z.Y. Ma, Achieving exceptionally high superplasticity at high strain rates in a micrograined Al-Mg-Sc alloy produced by friction stir processing, Scr. Mater. 59 (2008) 882-885, https://doi.org/10.1016/j.scriptamat.2008.06.035.

[14] F.C. Liu, Z.Y. Ma, Contribution of grain boundary sliding in low-temperature superplasticity of ultrafine-grained aluminum alloys, Scr. Mater. 62 (2010) 125-128, https://doi.org/10.1016/j.scriptamat.2009.10.010.

[15] N. Kumar, R.S. Mishra, C.S. Huskamp, K.K. Sankaran, Microstructure and mechanical behavior of friction stir processed ultrafine grained $\mathrm{Al}-\mathrm{Mg}-\mathrm{Sc}$ alloy, Mater. Sci. Eng. A 528 (2011) 5883-5887, https://doi.org/10.1016/j. msea.2011.03.109.

[16] F.C. Liu, Z.Y. Ma, F.C. Zhang, High strain rate superplasticity in a micro-grained Al$\mathrm{Mg}$-Sc alloy with predominant high angle grain boundaries, J. Mater. Sci. Technol. 28 (2012) 1025-1030, https://doi.org/10.1016/S1005-0302(12)60168-6.

[17] N. Kumar, R.S. Mishra, C.S. Huskamp, K.K. Sankaran, Critical grain size for change in deformation behavior in ultrafine grained Al-Mg-Sc alloy, Scr. Mater. 64 (2011) 576-579, https://doi.org/10.1016/j.scriptamat.2010.11.051.

[18] N. Kumar, R.S. Mishra, Additivity of strengthening mechanisms in ultrafine grained Al-Mg-Sc alloy, Mater. Sci. Eng. A 580 (2013) 175-183, https://doi.org/10.1016/j. msea.2013.05.006.

[19] F.C. Liu, P. Xue, Z.Y. Ma, Microstructural evolution in recrystallized and unrecrystallized Al-Mg-Sc alloys during superplastic deformation, Mater. Sci. Eng. A 547 (2012) 55-63, https://doi.org/10.1016/j.msea.2012.03.076.

[20] F.C. Liu, Z.Y. Ma, Superplasticity governed by effective grain size and its distribution in fine-grained aluminum alloys, Mater. Sci. Eng. 530 (2011) 548-558, https://doi.org/10.1016/j.msea.2011.10.018.

[21] G.R. Argade, N. Kumar, R.S. Mishra, Stress corrosion cracking susceptibility of ultrafine grained Al-Mg-Sc alloy, Mater. Sci. Eng. A 565 (2013) 80-89, https://doi. org/10.1016/j.msea.2012.11.066.

[22] S. Malopheyev, V. Kulitskiy, S. Mironov, D. Zhemchuzhnikova, R. Kaibyshev, Friction-stir welding of an Al-Mg-Sc-Zr alloy in as-fabricated and work-hardened conditions, Mater. Sci. Eng. A 600 (2014) 159-170, https://doi.org/10.1016/j. msea.2014.02.018.

[23] S. Malopheyev, S. Mironov, V. Kulitskiy, R. Kaibyshev, Friction-stir welding of ultra-fine grained sheets of Al-Mg-Sc-Zr alloy, Mater. Sci. Eng. A 624 (2015) 132-139, https://doi.org/10.1016/j.msea.2014.11.079.

[24] N. Kumar, R.S. Mishra, Ultrafine-grained Al-Mg-Sc alloy via friction-stir processing, Metall. Mater. Trans. A 44 (2013) 934-945, https://doi.org/10.1007/s11661-0121461-5.

[25] S. Malopheyev, S. Mironov, I. Vysotskiy, R. Kaibyshev, Superplasticity of frictionstir welded Al-Mg-Sc sheets with ultrafine-grained microstructure, Mater. Sci. Eng. A 649 (2016) 85-92, https://doi.org/10.1016/j.msea.2015.09.106.

[26] V. Kulitskiy, S. Malopheyev, S. Mironov, R. Kaibyshev, Grain refinement in an AlMg-Sc alloy: equal channel angular pressing versus friction-stir processing, Mater. Sci. Eng. A 674 (2016) 480-490, https://doi.org/10.1016/j.msea.2016.08.021.

[27] K. Wang, F.C. Liu, P. Xue, D. Wang, B.L. Xiao, Z.Y. Ma, Superplastic constitutive equation including percentage of high-angle grain boundaries as a microstructural parameter, Metall. Mater. Trans. A 47 (2016) 546-559, https://doi.org/10.1007/ s11661-015-3230-8. 
[28] D. Zhemchuzhnikova, S. Malopheyev, S. Mironov, R. Kaibyshev, Cryogenic properties of Al-Mg-Sc-Zr friction-stir welds, Mater. Sci. Eng. A 598 (2014) 387-395, https://doi.org/10.1016/j.msea.2014.01.060.

[29] N. Kumar, M. Komarasamy, R.S. Mishra, Plastic deformation behavior of ultrafinegrained Al-Mg-Sc alloy, J. Mater. Sci. 49 (2014) 4202-4214, https://doi.org/ 10.1007/s10853-014-8115-5.

[30] D. Zhemchuzhnikova, S. Mironov, R. Kaibyshev, Fatigue performance of frictionstir welded Al-Mg-Sc alloy, Metall. Mater. Trans. A 48 (2017) 150-158, https:// doi.org/10.1007/s11661-016-3843-6.

[31] D. Zhemchuzhnikova, A. Mogucheva, R. Kaibyshev, Mechanical properties and fracture behavior of an Al-Mg-Sc-Zr alloy at ambient and subzero temperature, Mater. Sci. Eng. A 565 (2013) 132-141, https://doi.org/10.1016/j. msea.2012.12.017.

[32] F.J. Humphreys, Quantitative metallography by electron backscattered diffraction, J. Microsc. 195 (1999) 170-185, https://doi.org/10.1046/j.1365 2818.1999.00578.x.

[33] R.W. Fonda, K.E. Knipling, Texture development in friction stir welds, Sci. Technol. Weld. Join. 16 (2011) 288-294, https://doi.org/10.1179/ 1362171811 Y.0000000010.

[34] F.J. Humphreys, M. Hatherly, Recrystallization and Related Phenomena, Elsevier, Oxford, 2004, p. 574.

[35] O. Sitdikov, T. Sakai, E. Avtokratova, R. Kaibyshev, Y. Kimura, K. Tsuzaki, Grain refinement in a commercial Al-Mg-Sc alloy under hot ECAP conditions, Mater. Sci. Eng. A 444 (2007) 18-30, https://doi.org/10.1016/j.msea.2006.06.081.

[36] O. Sitdikov, T. Sakai, E. Avtokratova, R. Kaibyshev, K. Tsuzaki, Y. Watanabe, Microstructure behavior of Al-Mg-Sc alloy processed by ECAP at elevated temperature, Acta Mater. 56 (2008) 821-834, https://doi.org/10.1016/j. actamat.2007.10.029.

[37] A. Mogucheva, E. Babich, B. Ovsyannikov, R. Kaibyshev, Microstructural evolution in a 5024 aluminum alloy processed by ECAP with and without back pressure, Mater. Sci. Eng. A 560 (2013) 178-192, https://doi.org/10.1016/j. msea.2012.09.054.

[38] T.J. Harrell, T.D. Topping, H. Wen, T. Hu, J.M. Schoenung, E.J. Lavernia, Microstructure and strengthening mechanisms in an ultrafine grained Al-Mg-Sc alloy produced by powder metallurgy, Metall. Mater. Trans. A 45 (2014) 6329-6343, https://doi.org/10.1007/s11661-014-2569-6.

[39] E.L. Huskins, B. Cao, K.T. Ramesh, Strengthening mechanisms in an Al-Mg alloy, Mater. Sci. Eng. A 527 (2010) 1292-1298, https://doi.org/10.1016/j. msea.2009.11.056.

[40] S. Malopheyev, V. Kulitskiy, R. Kaibyshev, Deformation structures and strengthening mechanisms in an Al-Mg-Sc-Zr alloy, J. Alloy. Comp. 698 (2017) 957-966, https://doi.org/10.1016/j.jallcom.2016.12.289.

[41] O. Ryen, O. Nijs, E. Sjolander, B. Holmedal, H.-E. Ekstrom, E. Nes, Strengthening mechanisms in solid solution aluminum alloys, Metall. Mater. Trans. A 37 (2006) 1999-2006, https://doi.org/10.1007/s11661-006-0142-7.

[42] S. Malopheyev, R. Kaibyshev, Strengthening mechanisms in a Zr-modified 5083 alloy deformed to high strains, Mater. Sci. Eng. A 620 (2014) 246-252, https://doi. org/10.1016/j.msea.2014.10.030.

[43] J. Kang, R.K. Mishra, D.S. Wilkinson, O.S. Hopperstad, Effect of Mg content on Portevin-Le-Chatelier band strain in Al-Mg sheets alloys, Philos. Mag. Lett. 92 (2012) 647-655, https://doi.org/10.1080/09500839.2012.714082.

[44] K.L. Kendig, D.B. Miracle, Strengthening mechanisms of an Al-Mg-Sc-Zr alloy, Acta Mater. 50 (2002) 4165-4175, https://doi.org/10.1016/S1359-6454(02)00258-6. 